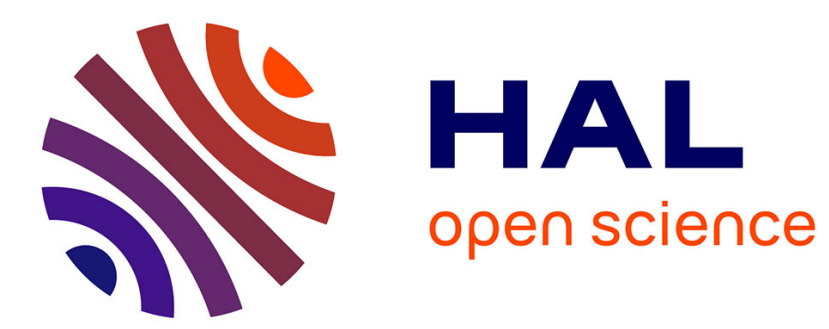

\title{
Defining Engagement and Characterizing Engaged-Behaviors in Digital Gaming
}

Patrice Bouvier, Elise Lavoué, Karim Sehaba

\section{To cite this version:}

Patrice Bouvier, Elise Lavoué, Karim Sehaba. Defining Engagement and Characterizing Engaged-Behaviors in Digital Gaming. Simulation and Gaming, 2014, 45 (4-5), pp.491-507. 10.1177/1046878114553571. hal-01131205

\section{HAL Id: hal-01131205 \\ https://hal.science/hal-01131205}

Submitted on 16 Mar 2015

HAL is a multi-disciplinary open access archive for the deposit and dissemination of scientific research documents, whether they are published or not. The documents may come from teaching and research institutions in France or abroad, or from public or private research centers.
L'archive ouverte pluridisciplinaire HAL, est destinée au dépôt et à la diffusion de documents scientifiques de niveau recherche, publiés ou non, émanant des établissements d'enseignement et de recherche français ou étrangers, des laboratoires publics ou privés. 


\title{
Defining Engagement and Characterizing Engaged-Behaviors in Digital Gaming
}

\author{
Patrice Bouvier ${ }^{1,2}$ \\ Elise Lavoué ${ }^{3}$ \\ Karim Sehaba ${ }^{1,4}$ \\ ${ }^{1}$ Université de Lyon, CNRS \\ ${ }^{2}$ Université Lyon 1, LIRIS, UMR5205, F-69622, France \\ ${ }^{3}$ Magellan, IAE Lyon, Université Jean Moulin Lyon 3 \\ ${ }^{4}$ Université Lyon 2, LIRIS, UMR5205, F-69676, France
}

\begin{abstract}
While the analysis of engagement is crucial for digital entertainment or learning games, the concept of players' or learners' engagement is still confusing. Indeed, in digital games research, several concepts referring to the idea of engagement such as immersion, involvement, presence and flow are used. Also, while the characterization of engaged-behaviors may be useful for designers or teachers in assessing players' or learners' engagement, the nature and the scope of these behaviors is still unclear. In this article, based on a multidisciplinary state of the art on the concept of engagement, we define and delineate the concepts related to digital gaming engagement. We also characterize engaged-behaviors by identifying four types of engagement: environmental, social, self and action. We thus refine, disambiguate and characterize the concepts of engagement and engaged-behaviors. This work therefore constitutes an effective support for analyzing, designing, assessing and personalizing engaging activities in digital games.
\end{abstract}

KEYWORDS: Digital Games; Engaged-Behaviors; Engagement; Flow; Immersion; Involvement; Presence

1 Introduction

For several years, there has been a growing interest of computer-supported education practitioners in digital game-based learning. In classroom lessons, teachers have the opportunities to assess students' engagement and to influence this by adapting the lesson. But with computer-supported education, the relationship between teachers and students is limited, especially in the case of distance learning. Information about learners' engagement may help teachers to maintain learners' motivation and so prevent school dropout. At the same time, the entertainment video game industry is undergoing important economic changes. The Free-to-Play economic model is gradually replacing the old Pay-to-Play economic model where the player has to buy the game before playing. In this new model, access to the game is free but the gameplay encourages players to pay for additional content (a new character, a new level or map, customization of the character's appearance or improvement of the character's skills and equipment). This economic transformation has many advantages for these companies, such as changing the game after its release (bug fixes, new products or features). Several versions of the game may also be deployed at the same time or in order to fight against piracy. In return, with free games access, it is very easy for players to move from one game to another. So, in order to keep players' loyalty in such a volatile and competitive market, companies seek to elicit and maintain players' engagement. 
In these two domains, continuously identifying and analyzing players' or learners' engagement (i.e. session after session) and under ecologically valid conditions (i.e. at home) is crucial (Takatalo, Häkkinen, Kaistinen, \& Nyman, 2011). A promising solution consists in detecting engaged-behaviors through the analysis of players' or learners' behaviors while they are playing. Thus, the first step towards this goal is to characterize players' engaged-behaviors. This is the object of this article. As the nature of engagement is still confusing (Boyle, Connolly, Hainey, \& Boyle, 2012), two questions must be answered in order to reach this goal:

1. What is engagement, i.e. what does it mean to be engaged?

2. How can player's engaged-behaviors be defined, i.e. how can it be decided whether a behavior reflects engagement or not?

The article is organized as follow. First, we refine the notions related to the concept of players' engagement. Then, we present the four types of engaged-behaviors we identified. Finally, we show the implications of our work in the gaming field.

\section{Defining engagement}

The interest in the concept of engagement, used in a broad sense, is shared by many application domains such as marketing (Greenwald \& Leavitt, 1984), the theory of communication (Wirth, 2006), human-robot interaction (Rich, Ponsleur, Holroyd, \& Sidner, 2010), Web applications (Attfield, Kazai, Lalmas, \& Piwowarski, 2011), digital games (Boyle et al., 2012), virtual reality (Schubert, Friedmann, \& Regenbrecht, 2001), education (Reeve, Jang, Carrell, Jeon, \& Barch, 2004) or game-based learning (Garris, Ahlers, \& Driskell, 2002).

In the context of web applications, Attfield et al. (2011) define user engagement as "the emotional, cognitive and behavioral connection that exists, at any point in time and possibly over time, between a user and a resource" (p. 2). This definition is interesting as it reflects the different manifestations of engagement (emotional, cognitive and behavioral). However, we prefer a more conceptual definition and regret that the authors do not more precisely specify these three dimensions of engagement.

In the context of human-robot interaction, Sidner, Kidd, Lee and Lesh (2004) consider engagement as "the process by which two (or more) participants establish, maintain and end their perceived connection during interactions they jointly undertake" (p. 1). The interest of this vision is that it considers engagement as a psychological and behavioral link.

In the field of education, engagement may be considered as the "behavioral intensity and emotional quality of a person's active involvement during a task" (Reeve et al., 2004, p. 143). After reviewing the concept of school engagement, Fredricks, Blumenfeld and Paris (2004) conclude that engagement is a "meta construct" (p. 60) that 
encompasses "behavioral" (participation, positive conduct, effort), "emotional" (interest, positive emotions) and "cognitive" (psychological involvement in learning, self-regulation) dimensions.

This quick overview of engagement highlights the significance of engagement for many areas. We can also observe that these definitions are context-dependent. In this article, we specifically deal with engagement in the digital game field.

\subsection{Several terms for several overlapping concepts}

Boyle et al. (2012) observe in their systematic review on engagement in digital gaming that the nature of engagement is still not clearly understood. Engagement remains a confusing concept that encompasses several notions and depends on a large number of technical and human interrelated factors.

Moreover, in the digital game area, several concepts such as attention, immersion, involvement, presence and flow refer to the idea of engagement. Takatalo, Häkkinen, Kaistinen and Nyman (2010) notice that "Often these concepts are defined quite broadly [...] Thus there is a great overlap among the concepts and as a consequence, numerous challenges to understanding and actually measuring them.“" (p. 27).

Based on a multidisciplinary state of the art on the concept of engagement, we provide an accurate and consistent terminology for disambiguating and focusing these terms.

\subsubsection{Attention}

User attention is often highlighted as being a crucial factor of engagement or immersion. Brown and Cairns (2004) described attention as the willingness to concentrate. Attention refers to the set of processes that enables and guides the selection of perceptual information (Roda \& Thomas, 2006). Attention is therefore focused on the location judged the most relevant to acquire and process the information. Attention here has three dimensions: the target area, the intensity and the duration. There are two kinds of attention: captured (by an event or an external stimulus such as a flash light) and controlled (attention here is voluntarily focused on an environment area of particular interest). In the latter case, the content of the activity will play a decisive role in the allocation of attention. We agree with (Brown \& Cairns, 2004) in considering attention as a crucial factor of engagement.

\subsubsection{Immersion}

Immersion is very likely the most common word used by gamers, designers and game researchers (Jennett et al., 2008). Several studies have been conducted in order to define and understand immersion. Brown and Cairns (2004) define it as an "intense experience" that describes "a scale of involvement with a game". Ermi and Mäyrä (2005) highlight three components of immersion: "sensory immersion" that refers to the visual properties 
of the game, "challenge-based immersion" that focuses on the player's skills and challenges and "imaginative immersion" that appears when players are absorbed in the narrative aspects of the game or identify with a character. For Jennett et al. (2008) immersion is "the result of a good gaming experience". This is shown by a loss of sense of time, by forgetting the real environment and a feeling of being in the game environment.

The previous overview highlights that immersion can both refer to the features of the game (its visual realism, the technologies used to render the environment of the game etc.) and to the players' responses and experiences (like players' interest, attachment or psychological absorption). Thus immersion "has become an excessively vague, all-inclusive concept" (McMahan, 2003, p. 67). This debate already occurred in virtual reality research (Slater, 1999). Recently, Slater (2009) proposed to restrict immersion to the description of the sensorimotor contingencies supported by a system.

We also believe that for the same immersive characteristics of a game, player's responses and experiences can be different, and therefore it is not relevant for the concept of immersion to refer both to the players' responses and experiences and to the features of the game. In agreement with Slater (2009), we define immersion as the objective and measurable description of means and methods implemented to ensure the perception, the understanding and thus, the appropriation of the game world. Therefore, the objective of the immersion is the stimulation of player's senses in order to replace the perception of the real environment by the rendering of the game world.

\subsubsection{Involvement}

Calleja (2007) identifies six frames of players' involvement: tactical (the elaborated strategy), performative (controls and movements), shared (social aspects), narrative (content), affective (aesthetic and pleasure), spatial (the virtual world). This way of clearly defining the facets of players' involvement is highly relevant. However, we disagree with this proposition on several aspects. For example, why should pleasure be considered as a component on its own, as pleasure is probably present in any of the other components (pleasure of sharing with another player or completing a challenge)? In section 3, we describe how we characterize the four dimensions of players' engagement.

Wirth et al. (2007) consider involvement as the "active and intensive processing of the mediated world" (p. 513). In this case, a user participates voluntarily and intentionally in a process of exchange of information. This can have a cognitive dimension (attention, reasoning, judgment), an emotional dimension (relationships between the content, interests and previous experiences) and a behavioral dimension (willingness to act and to explore in particular). 
We adopt an approach close to the latter by defining involvement as the willingness to exchange information with the system through the interaction devices. Exchanging information means acquiring or communicating information from or to the system. Thus involvement depends on the relevance, in the context of the game, of the interaction tools and modalities.

\subsubsection{Presence}

The feeling of presence is a crucial consideration in virtual reality research as a user who feels presence may react and behave as if the environment and the situation are real (Sanchez-Vives \& Slater, 2005). The research community has proposed several definitions but certain notions have emerged. Presence can be seen as the feeling of being there, in the virtual environment rather than in the physical one (Slater \& Usoh, 1993). Lombard and Ditton (1997) defined presence as a "perceptual illusion of non mediation". More recently, Slater (2009) suggested considering presence as a combining of "place illusion" (which refers to the common idea of being there) and "plausibility illusion" of the situation virtually depicted.

We define presence as the genuine feeling of existing in a world other than the physical world in which the body is. The term feeling states that presence is a subjective experience felt consciously, that depends on user's internal and external factors. Furthermore, although aware of the virtuality of the situation, the participant experiences a real and sincere (genuine) feeling of existing in the virtual world. The notion of existing includes the generally accepted idea of moving and acting in the virtual environment, but also the innovative idea that the participant has to embody a role. The role can be the one intended by the mediated activity or another one independently chosen by the participant. Embodying the role requires the participants to be aware of their actions and their consequences. And it is only when users embody a role, rather than just a virtual body, that they may react and behave as if the environment and situation are real. Thus, presence is neither an emotional response nor a simple impression of being in the virtual environment.

\subsubsection{Flow}

Csikszentmihalyi (Csikszentmihalyi, 1991) conceptualized flow as "the optimal experience". Flow is a mental state of intense concentration in which a person is completely absorbed in her/his task and the situation. Flow comes from the balance between users' skills and the challenges to be taken up. If this balance is achieved then feelings of pleasure, self-fulfillment and total control of the activity occur and are accompanied by a time distortion.

As flow is intrinsically linked to an optimal balance between user skills and challenge, we consider flow as a subcomponent of the presence state, focused on the challenge dimension of the player's experience. 


\subsubsection{Engagement}

Brown and Cairns (2004) define engagement as the lowest level of immersion before "engrossment" and "total immersion". Based on their synthesis from several theories, O'Brien and Toms (2008) describe an interesting process of engagement: "point of engagement", "engagement", "disengagement" and "reengagement" (p. 10). The authors define engagement as "a quality of user experiences with technology that is characterized by challenge, aesthetic and sensory appeal, feedback, novelty, interactivity, perceived control and time, awareness, motivation, interest, and affect." (O'Brien \& Toms, 2008, p. 23). This definition, too factual, mixes factors and outcomes of engagement, but does not really characterize engagement. Brockmyer et al. (2009) consider engagement as "a generic indicator of game involvement" (p. 624). Thus, engagement can evolve on a progressive scale whose levels are immersion, presence, flow and psychological absorption (total engagement). This progressive aspect is interesting but here again one can ask about involvement (and about the other concepts). Chen, Kolko, Cuddihy and Medina (2011) defined engagement as "a sustained level of involvement caused by capturing a person's interest, holding the majority of a person's attentional resources, and placing the person in an immersive state" (p. 3). The authors provide a technical definition that describes the process of engagement rather than the state of engagement.

The first issue with these definitions is the reference to ambiguous concepts like involvement or immersion. The second issue is that these definitions are operational and/or technical definitions. Thus, they are too contextdependent and typically seem rather to specifically address immersive games (with high-level graphics or immersive interfaces). As we aim to provide a definition that works with all the types of games (such as high or low immersive and interactive features, entertaining or learning games), we think it more relevant to consider a conceptual definition that focuses on the state of engagement rather than its factors or outcomes.

Therefore, we consider engagement as the willingness to have emotions, affect and thoughts directed towards and aroused by the mediated activity in order to achieve a specific objective. The latter depends on both the activity and the players' expectations. Engagement occurs if players' expectations (perceptual, intellectual, interactional) are fulfilled. Then, in a process similar to the "suspension of disbelief" (Coleridge, 1969), players and learners may willing become engaged in order to live the activity more intensely. So they accept the fact that, during a given time, which may continue beyond the duration of the mediated activity, their emotions, affect and thoughts will be mainly elicited by the mediated activity (here the digital game). For example engaged-players may think back to the previous session or anticipate the next one. Lastly, although proposed in the context of digital games, this definition of engagement can be applied to most mediated (technological and social) activities (at least those that can be engaging such as web, online social networking, etc.).

1 Suspension of disbelief is the willingness to accept, despite the technical or narrative shortcomings, a fictional work as being reality. 


\subsection{Positioning of the concepts}

The precise terminology proposed above enables us to position the different concepts according to the shifting of players' attention and consciousness, from the real world to the virtual world (from the game environment to the game itself). Figure 1 illustrates our proposition for disambiguating these concepts. In this representation, we consider player's attention and consciousness as two sliders in the process of engagement. Damasio and Meyer (2008) described consciousness as "a momentary creation of neural patterns that describe a relation between the organism, on the one hand, and an object or event, on the other" (p. 6). In the present case this relation could be established between the players and the real world or between the players and the game world.

The concepts of immersion and involvement belong to the media factors. Thus they refer to the form of the mediated activity. The content factor concerns what is perceived (the situation and the scenario depicted). The player factor refers to players' expectations that depend on their characteristics (age, gender, psychology, cognitive or physical abilities, skills but also previous experiences, specific mood, motivations and needs). Initially, players' attention and consciousness are focused on the real world.

The objective of the content and media factors is to encourage the shift in players' attention from the real world towards the game world. Thus, the game world and the interaction tools and modalities become the players' mixed reference environment. If the content and media factors fulfill the players' perceptual, intellectual, interactional expectations, then players may agree to suspend their disbelief in order to get engaged. It is only after this last stage that players achieve an experiential level composed of the concepts of engagement, presence and flow. When players are engaged, their attention is directed towards the content of the activity. According to the content and to players' expectations, players will adopt a certain type of engaged-behavior (see section 3). As engagement does not require a loss of mental contact with the real world (engaged players can still be aware of their surroundings), players' consciousness is still directed towards the real world.

By contrast, presence and flow are defined as experiences that require the shift in consciousness from the real world to the activity world. So we consider presence as a state that may occur after engagement. Indeed, while all games may be engaging, only some may elicit a feeling of presence: simulation or role-playing game can elicit presence but not Tetris (while being very engaging). As explained in section 2.1.5, flow is considered as a part of presence, focused on the action dimension (challenge). 


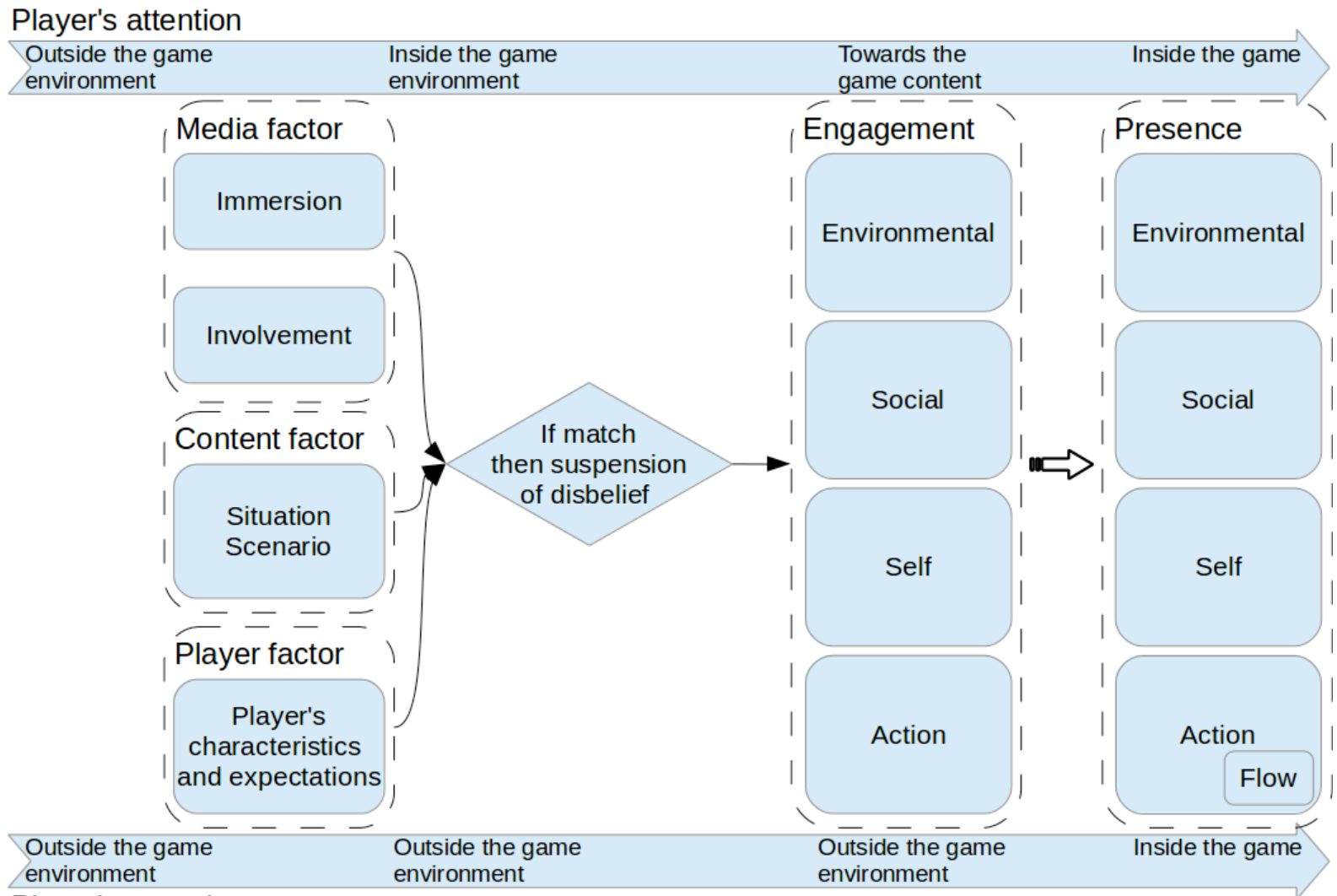

\section{Player's consciousness}

FIGURE 1: Players' attention and consciousness shifting from immersion and involvement to engagement, presence and flow

\section{Characterizing Engaged-Behaviors}

In this section, we first consider the question of the players' motives and needs that determine engagement. This perspective is different from other works mainly based on empirical observations on users' behavior. This enables us to determine a wide and non-stereotyped range of engaged-behaviors.

\subsection{Players' motives}

We consider that players' behaviors are conditioned by their motives or by the gameplay ${ }^{2}$ of the game. When fully determined by the gameplay of the game, behaviors are too trivial to reflect any attachment to the game. To determine whether behavior reflects an engagement or not, we have to address the question of players' motivations for playing games. This means addressing the question of the motives that determine engagement and so, establishing the relationship between motives and players' actions in the game. This is useful in order to give meaning, in relation to their engagement, to players' behaviors within the game.

2 In digital gaming, gameplay is a blanket term that refers to the structure, the dynamics or the interactive aspects of a game. 
Lazzaro (2004) identifies four motivational factors labeled "hard fun” (challenge), "easy fun” (curiosity, fantasy), "altered state" (positive emotions), and "people factor" (social experiences). Yee (2006) observes three main components: "achievement", "social" and "immersion". However, as these works are based on empirical observations of players' behaviors in specific games, the motivational factors identified depend on the gameplay of the game. Furthermore, as noted by Lazzaro (2004), people play games not for the game itself but for the emotions and the experience the game provokes.

To determine the motivational factors behind digital game engagement, many researchers have considered theories on universal Human psychological needs (Przybylski, Rigby, \& Ryan, 2010; Sherry, Lucas, Greenberg, \& Lachlan, 2006). In agreement with (Przybylski et al., 2010), we use the Self-Determination Theory (SDT) (Ryan \& Deci, 2000) to explain digital game engagement. The SDT identifies three basic psychological needs: competence (sense of efficacy), autonomy (volition and personal agency) and relatedness (social interaction). It is easy to observe that digital games have the ability to fulfill these needs. This may explain why people play games. We consider that Human psychological needs are in fact, the need to feel the corresponding emotions. We also assume that in a process similar to the suspension of disbelief (Coleridge, 1969), players may willingly become engaged in order to feel these emotions more intensely. Thus, as our definition of engagement indicates, players' behavior is determined by the emotions sought, and the emotions felt during the game are the motives for playing.

The basic psychological needs perspective can be applied to all types of games (and corresponding gameplays). Being versatile, this approach enables us to determine a wide, non-stereotyped range of behaviors. Thus, to qualify behaviors of being engaged, we link users' behaviors to the universal needs (identified by the SDT) that they satisfy and the corresponding emotions that they elicit.

\subsection{Four types of engaged-behaviors}

For structuring the analysis of engaged-behaviors, we consider that digital gaming consists in performing some actions (decision-making process), directly or through a character, within an environment (or at least a frame), that may involve social interaction with human or virtual agents (Bouvier, Lavoué, Sehaba, \& George, 2013). Based on our definition of engagement and on the SDT theory, we identify four types of engaged-behaviors:

- Environment-directed, in relation to the need for autonomy.

- Social-directed, in relation to the need for relatedness

- $\quad$ Self-directed, in relation to the need for autonomy.

- Action-directed, in relation to the needs for competence and autonomy

Each type encompasses several behaviors already observed in previous works (Lazzaro, 2004), (Yee, 2006), 
(Calleja, 2007) and (Poels, de Kort, \& Ijsselsteijn, 2007).

According to the type of game, these behaviors will not always be present, nor with the same intensity. We detail below each type of engaged-behavior.

\subsubsection{Environment-directed engaged behaviors}

Players' engagement can be directed towards the environment or the world depicted in the game. This engagement encompasses two main behaviors: contemplation and curiosity. Contemplatives like to stroll in the game area. Curious seek to know the physical and geographical boundaries of the game world. They want to understand the mechanics but also to discover the bugs, extra-content or carry out some exploit ${ }^{3}$. They may like to mod the games ${ }^{4}$. They may also be interested in configuring the features of the game. The goal of players who have environment-directed engaged behaviors is not to win but to increase their knowledge of the game.

The emotions sought are linked to escapism, curiosity, surprise, imagination, relaxation or aestheticism.

Environmental engagement depends on the vividness of the immersion, on the variety and aesthetics of the world and on the possibility of exploring or modifying the environment.

\subsubsection{Social-directed engaged behaviors}

Social engagement refers to the social connections within the game. In this case, the game is an opportunity for the players to create, expand or animate their social relations toward other players. Their purpose is to develop and maintain their social network. This type of players tends to use the communication channels provided, to promote the game and increase the number of participants and enjoy the teamwork (collaborative work in a serious game, within a team or guild in a digital game).

The emotions generated refer to the pleasure in social connectivity, like competition and collaboration and in social recognition. Social engagement relies on social interaction channels like chats, forums, messages or direct communication during the game. Some facilitators may also be provided in order to challenge other players or undertake a team quest. If virtual agents are met, it is important that they do not display stereotyped speech and behavior as players like to perceive some intelligence.

\subsubsection{Self-directed engaged behaviors}

Self-engagement concerns the connection between players and their character through identification and/or

\footnotetext{
3 An exploit is the use by a player, of a bug or feature of a game in a manner not intended by the game's designers

$4 \quad$ Modding a game consists in modifying some parts of the gameplay by introducing new features such as new maps, levels, objects or characters.
} 
ownership aspects. This kind of players likes to customize her/his avatar and chooses accessories for reasons other than performance. Players experiencing this type of engagement will be particularly involved in the personalizing stage (acquiring a new sword, a costume, skills etc.) in order to differentiate their character. Thus, they spend a long time studying the features of the accessories or skills. These players tend to care about the role-play.

The emotions elicited are the pleasure in possessing, managing an avatar and disguising themselves. The viewing mode is important for this type of engagement. Typically, third person vision fosters the player identification. The customization possibilities provided facilitate the appropriation of the avatar.

\subsubsection{Action-directed engaged behaviors}

Players' engagement is directed towards the actions to perform in the situation depicted by the game. The core of the game is the main interest for this type of player. For instance, they tend to try to pass the levels quickly, win experience points, and complete challenges. They may also define their own challenges.

The emotions generated concern accomplishment (goal achievements, completion), self-esteem, arousal and positive emotions related to physical movements in exertion games. The gameplay, the balance between player skills and challenges is crucial for this type of engagement (Cox, Cairns, Shah, \& Carroll, 2012). Players have to be aware of their actions and of their consequences in order to feel a sense of agency. This kind of player likes to feel in control.

\subsection{Summary}

As in the work of (Hassenzahl, Diefenbach, \& Göritz, 2010) on the categorization of users' experience with interactive products according to the primary needs they fulfill, in Table 1 we propose a categorization of engaged-behaviors according to the universal needs they fulfill and the corresponding emotions they elicit. 


\begin{tabular}{|c|c|c|c|c|}
\hline & $\begin{array}{l}\text { Environmental } \\
\text { engagement }\end{array}$ & $\begin{array}{l}\text { Social } \\
\text { engagement }\end{array}$ & $\begin{array}{l}\text { Self } \\
\text { engagement }\end{array}$ & $\begin{array}{l}\text { Action } \\
\text { engagement }\end{array}$ \\
\hline $\begin{array}{l}\text { SDT basic } \\
\text { psychological needs }\end{array}$ & $\begin{array}{l}\text { Autonomy towards } \\
\text { the environment }\end{array}$ & Relatedness & $\begin{array}{l}\text { Autonomy towards } \\
\text { the character }\end{array}$ & $\begin{array}{l}\text { Competence } \\
\text { Autonomy towards } \\
\text { the actions }\end{array}$ \\
\hline Elicited emotions & $\begin{array}{l}\text { Escapism, } \\
\text { Curiosity, Surprise, } \\
\text { Imagination, } \\
\text { Relaxation, } \\
\text { Aestheticism }\end{array}$ & $\begin{array}{l}\text { Pleasure in social } \\
\text { connectivity, } \\
\text { collaboration, } \\
\text { competition, } \\
\text { social recognition }\end{array}$ & $\begin{array}{l}\text { Pleasure in } \\
\text { possessing or } \\
\text { managing an avatar, } \\
\text { Pleasure in } \\
\text { disguising } \\
\text { themselves }\end{array}$ & $\begin{array}{l}\text { Accomplishment, } \\
\text { Self-esteem, Arousal }\end{array}$ \\
\hline Players' behavior & $\begin{array}{l}\text { Contemplative, } \\
\text { Curious, } \\
\text { Exploration, } \\
\text { Modding }\end{array}$ & $\begin{array}{l}\text { Expanding social } \\
\text { network, Livening } \\
\text { up the group of } \\
\text { actual friends, } \\
\text { Sharing moments } \\
\text { with others }\end{array}$ & $\begin{array}{l}\text { Customizing the } \\
\text { character, } \\
\text { Developing a story } \\
\text { around the } \\
\text { character }\end{array}$ & $\begin{array}{l}\text { Mastering the game, } \\
\text { Completing } \\
\text { challenge, } \\
\text { Practicing, } \\
\text { Elaborating a } \\
\text { strategy }\end{array}$ \\
\hline
\end{tabular}

Table 1: Examples of (non-exhaustive) players' behaviors associated with the needs they fulfill and the emotions elicited according to the four types of engaged-behaviors

\section{$4 \quad$ Discussion and applications}

This theoretical work on engagement and engaged-behaviors has several applications in the digital gaming field. The present work enables us to clarify the nature of engagement (by defining and delineating the concept of engagement and by positioning it relative to other concepts) and the nature of engaged-behaviors (by basing engaged-behaviors on a satisfaction of needs theory). Our work highlights that engagement depends on users' characteristics (such as motives, expectations, abilities and skills) and on the form, content and context of the activity. In our terminology, engagement might be a concept easier to grasp and to identify than the broad user experience in games (Bernhaupt, 2010). Thus, our contribution provides a relevant theoretical basis for designers, practitioners and teachers in order to analyze and design engaging experience in digital gaming. We consider it important, during the design of a game, to think about the expected type of engaged-behaviors (for instance an activity may require a social engagement rather than an action engagement). Engagement and presence may also be considered as two human-centered indicators of the effectiveness of the activity (the relevance of the form of the activity, the authenticity of the content). They may be used to evaluate the Quality of Experience of the activity or to validate the mediated activity. Assessing players' or learners' engagement during the activity may also support the adaptation and the personalization of the activity (its content and/or the 
system).

We have used this contribution as a theoretical basis on which to define an approach identifying and qualifying players' and learners' engagement from their traces of interaction (Bouvier et al., 2013). This work has been conducted in the context of the QUEJANT project that involves companies specialized in the development of social games. As digital games offer a large variety of actions, we sought to determine whether an action belongs to high-level behavior reflecting an engagement or not. We have used the present work on engaged-behaviors to determine the chains of actions underpinning an engaged-behavior. In (Bouvier, Sehaba, Lavoué, \& George, 2013) we present a user study that demonstrates that our approach enables us to distinguish between engagedplayers and non-engaged players and to qualify their type of engaged-behaviors (unique or mixed regarding the four types of engaged-behaviors). For example, we were able to differentiate and identify two types of social engagement (one directed toward the existing players' friends, the other directed toward unknown players). The companies involved in the QUEJANT project were interested in these results so as to adapt the game in order to elicit and maintain players' engagement.

The analysis of engagement and engaged-behaviors could also be useful for teachers or tutors in conducting debriefing sessions with learners. Being informed by the system of the type(s) of engagement(s) of each participant, teachers or tutors can understand the behavior of the learners during the computer-mediated activity (engaged or not and the reasons why). They can use this information to organize and personalize the debriefing with the participants. Teachers and tutors can also discuss with learners their engagement (or non-engagement) and their type of engagement, so that learners can reflect on their behavior during the activity. The information analyzed by the system (engagement and engaged-behaviors) can also be given directly to learners to provoke and support reflexive processes. For instance, this information may incite them to talk about their feelings and emotions during the activity, and maybe think about the gap between these feelings and the information automatically analyzed by the system.

\section{Conclusion}

In this article, we first refined and disambiguated several concepts close to the notion of engagement: attention, immersion, involvement, presence and flow. We then provided a precise definition of engagement in digital gaming. This contribution is useful in order to facilitate scientific exchanges, especially when the concept of engagement is used in several fields. This work enables us to make a distinction between the technical components (immersive and interactive dimensions), the content component of the game (narrative, challenges etc.) and the player's experience (engagement, flow or presence). Thus our work may help to clarify the object of a research (by specifying what is aimed at or what is being measured). In this way, it improves the validity and the effectiveness of the comparisons between several methods or approaches. It also helps to identify players' engaged-behaviors within a game. 
To decide whether a behavior reflects an engagement or not, we studied players' motives and especially the universal Human psychological needs defined in the Self-Determination Theory (SDT). We used this theory and the proposed definition of engagement to identify four types of engaged-behaviors: environment-directed, socialdirected, self-directed and action-directed. These types of engaged-behaviors encompass several players' behaviors. We thus establish a relationship between needs and emotions sought after (considered as true motives of engagement) and the four generic types of player's engaged-behaviors. By relying on the SDT, our proposition does not depend on the gameplay of the game and so can be applied to the analysis of any type of game.

At present, this theoretical work has been used to analyze interaction traces in social games. This analysis enabled us to identify engaged and non-engaged players, and the types of engaged behaviors. From a practical viewpoint, our future works will be conducted in order to provide game designers with this information synthetically, for example on a chart, so that they can adapt the game according to this information. In a more theoretical way, during our user study we observed that some players adopt a single type of engaged-behavior while others adopt mixed engaged-behaviors. We will examine the question of whether these mixed engagedbehaviors are balanced between the different types or if players have a main type of engaged-behavior, the secondary ones being adopted only to support this. Also, if the dominant players' engagement (environment, social, self or action) evolves session after session, does that means that this evolution depends on players' intrinsic factors (such as mood or motivation) or extrinsic factors (new game design, new features)? In other words, is it possible to deliberately modify the type of engaged-behavior?

\section{Acknowledgements}

This research has been conducted within the QUEJANT project which involved the LIRIS Laboratory and the video games companies Corexpert, Intellysurf and Kiniro. The QUEJANT project was labelled by the french competitiveness cluster Imaginove.

The authors thank the reviewers and editors of this special issue for their insightful and constructive comments and suggestions.

Declaration of Conflicting Interests

The authors declared no conflicts of interest with respect to the authorship and/or publication of this article.

\section{Funding}

Funding for this project was provided by a grant from la Région Rhône Alpes and Le Grand Lyon.

Author contributions

All authors contributed substantially to this article. 
References

Attfield, S., Kazai, G., Lalmas, M., \& Piwowarski, B. (2011). Towards a science of user engagement (Position Paper). Procceedings of WSDM Workshop on User Modelling for Web Applications (p. 8).

Bernhaupt, R. (2010). Evaluating user experience in games: Concepts and methods (1st ed.). London: Springer.

Bouvier, P., Lavoué, E., Sehaba, K., \& Sébastien, G. (2013). Identifying learner's engagement in learning games: A qualitative approach based on learner's traces of interaction. Proceedings of CSEDU 2013: The 5th International Conference on Computer Supported Education (pp. 339-350). Aachen, Germany.

Bouvier P., Sehaba K., Lavoué E. \& George S. (2013). Using traces to qualify learner's engagement in game-based learning. Proceedings of ICALT 2013: The 13th IEEE International Conference on Advanced Learning Technologies (pp. 432-436). Beijing, China : IEEE Computer Society.

Boyle, E. A., Connolly, T. M., Hainey, T., \& Boyle, J. M. (2012). Engagement in digital entertainment games: A systematic review. Computers in Human Behavior, 28(3), 771-780.

Brockmyer, J. H., Fox, C. M., Curtiss, K. A., McBroom, E., Burkhart, K. M., \& Pidruzny, J. N. (2009). The development of the Game Engagement Questionnaire: A measure of engagement in video game-playing. Journal of Experimental Social Psychology, 45(4), 624-634.

Brown, E., \& Cairns, P. (2004). A grounded investigation of game immersion. Proceedings of $\mathrm{CHI}$ '04 Extended Abstracts on Human factors in computing systems (pp. 1297-1300). New York, NY, USA: ACM.

Calleja, G. (2007). Revising immersion: A conceptual model for the analysis of digital game involvement. Proceedings of Situated Play, the 2007 Digital Games Research Association Conference (pp. 83-90). The University of Tokyo.

Chen, M., Kolko, B. E., Cuddihy, E., \& Medina, E. (2011). Modeling but not measuring engagement in computer games. Proceedings of GLS' 11: The 7th international conference on Games + Learning + Society Conference (pp 55-63), Pittsburgh, PA, USA. ETC Press.

Coleridge, S. T. (1969). The collected works of Samuel Taylor Coleridge. Routledge and K. Paul ; London: Princeton University Press.

Cox, A., Cairns, P., Shah, P., \& Carroll, M. (2012). Not doing but thinking: The role of challenge in the gaming experience. Proceedings of the 2012 ACM annual conference on Human Factors in Computing Systems (pp. 79-88). New York, NY, USA: ACM.

Csikszentmihalyi, M. (1991). Flow: The psychology of optimal experience. New York, NY: 
Harper Perennial.

Damasio, A., Meyer, K. (2008). Consciousness: An overview of the phenomenon and of its possible neural basis, in The Neurology of Consciousness (pp 3 - 14), Steven Laureys and Guilo Tononi (eds) Elsevier,

Ermi, L., \& Mäyrä, F. (2005). Fundamental components of the gameplay experience: Analysing immersion. Proceedings of the DiGRA Conference: Changing Views: Worlds in Play (p. 14). Vancouver, British Columbia, Canada. de Castell Suzanne \& J. Jennifer (Eds.)

Fredricks, J. A., Blumenfeld, P. C., \& Paris, A. H. (2004). School engagement: Potential of the concept, state of the evidence. Review of Educational Research, 74, 59-109.

Garris, R., Ahlers, R., \& Driskell, J. E. (2002). Games, motivation, and learning: A research and practice model. Simulation \& Gaming, 33(4), 441-467.

Greenwald, A. G., \& Leavitt, C. (1984). Audience involvement in advertising: Four levels. Journal of Consumer Research, 11(1), 581-592.

Hassenzahl, M., Diefenbach, S., \& Göritz, A. (2010). Needs, affect, and interactive products - Facets of user experience. Interacting with Computers, 22(5), 353-362.

Jennett, C., Cox, A. L., Cairns, P., Dhoparee, S., Epps, A., Tijs, T., \& Walton, A. (2008). Measuring and defining the experience of immersion in games. International Journal of Human-Computer Studies, 66(9), 641-661.

Lazzaro, N. (2004). Why We Play Games: Four keys to more emotion without story. Proceedings of The Game Developers Conference.

Lombard, M., \& Ditton, T. (1997). At the heart of it all: The concept of presence. Journal of computer-mediated communication, 3(2), 20.

McMahan, A. (2003). Immersion, engagement and presence: A method for analyzing 3D video games. In M.J.P. Wolf, B. Perron (Ed.), The Video Game Theory Reader (pp. 67-86). Routledge, New York.

O’Brien, H. L., \& Toms, E. G. (2008). What is user engagement? A conceptual framework for defining user engagement with technology. Journal of the American Society for Information Science, 59(6), 938-955.

Poels, K., de Kort, Y., Ijsselsteijn W. (2007). "It is always a lot of fun!": Exploring dimensions of digital game experience using focus group methodology. Proceedings of Future Play'07 the 2007 conference on Future Play, (pp 83-89).

Przybylski, A. K., Rigby, C. S., \& Ryan, R. M. (2010). A motivational model of video game engagement. Review of General Psychology, 14(2), 154-166.

Reeve, J., Jang, H., Carrell, D., Jeon, S., \& Barch, J. (2004). Enhancing students' 
engagement by increasing teachers' autonomy support. Motivation and Emotion, 28(2), 147-169.

Rich, C., Ponsleur, B., Holroyd, A., \& Sidner, C. L. (2010). Recognizing engagement in human-robot interaction. Proceedings of the 5th ACM/IEEE international conference on Human-robot interaction (pp. 375-382). Piscataway, NJ, USA: IEEE Press.

Roda, C., \& Thomas, J. (2006). Attention aware systems: Theories, applications and research agenda. Computers in Human Behavior, 22, 557-587.

Ryan, R. M., \& Deci, E. L. (2000). Self-determination theory and the facilitation of intrinsic motivation, social development, and well-being. The American Psychologist, 55, 68-78.

Sanchez-Vives, M. V, \& Slater, M. (2005). From presence to consciousness through virtual reality. Nature Reviews Neuroscience, 6(4), 332-339.

Schubert, T., Friedmann, F., \& Regenbrecht, H. (2001). The Experience of presence: Factor analytic insights. Presence: Teleoperators and Virtual Environments., 10(3), 266-281. doi:http://dx.doi.org/10.1162/105474601300343603

Sherry, J. L., Lucas, K., Greenberg, B. S., \& Lachlan, K. (2006). Video game uses and gratifications as predictors of use and game preference. Playing Video Games. Motives Responses and Consequences, 213-224. P. Vorderer \& J. Bryant, Eds.

Sidner, C. L., Kidd, C. D., Lee, C., \& Lesh, N. (2004). Where to look: A study of humanrobot engagement. Proceedings of the 9 th international conference on Intelligent user interfaces (pp. 78-84). New York, NY, USA: ACM.

Slater, M. (1999). Measuring presence: A response to the witmer and singer presence questionnaire. Presence: Teleoperators and Virtual Environments , 8(5), 560-565. doi:http://dx.doi.org/10.1162/105474699566477

Slater, M. (2009). Place illusion and plausibility can lead to realistic behaviour in immersive virtual environments. Philosophical Transactions of the Royal Society B: Biological Sciences, 364(1535), 3549-3557.

Slater, M., \& Usoh, M. (1993). Presence in immersive virtual environments. Proceedings of Virtual Reality Annual International Symposium, 1993., 1993 IEEE (pp. 90-96).

Takatalo, J., Häkkinen, J., Kaistinen, J., \& Nyman, G. (2010). Presence, involvement, and flow in digital games. In R. Bernhaupt (Ed.), Evaluating User Experience in Games: Concepts and methods (pp. 23-46). London: Springer.

Takatalo, J., Häkkinen, J., Kaistinen, J., \& Nyman, G. (2011). User experience in digital games differences between laboratory and home. Simulation \& Gaming, 42(5), 656673. 
Wirth, W. (2006). Involvement. In J. Bryant \& P. Vorderer (Eds.), Psychology of entertainment (pp. 199-213). Mahwah, S.

Wirth, W., Hartmann, T., Bocking, S., Vorderer, P., Klimmt, C., Schramm, H., Saari, T., Laarni, J., Ravaja, N., Ribeiro Gouveia, F., Biocca, F., Sacau, A., Jäncke, L., Baumgartner, T, \& Jäncke, P. (2007). A process model of the formation of spatial presence experiences. Media Psychology, 9(3), 493-525.

Yee, N. (2006). Motivations for play in online games. Cyberpsychology and Behavior, $9(6), 772-775$.

Bios

Patrice Bouvier received his Ph.D. in Computer Science from the Université Paris-Est (France) in 2009. His research focuses on the user experience during a mediated activity (social and technological). Presence in virtual reality during his Ph.D (Title: Presence in virtual reality, a user centred approach). Engagement and engagedbehaviours in entertainment or learning games during his post-doc (QUEJANT project). Contact:

pbouvier.pro@gmail.com

Elise Lavoué is an Associate Professor of Computer Science at the University Jean Moulin Lyon 3 (France), MAGELLAN Research Centre. She is also a collaborator of the LIRIS Laboratory. Her research interests include: Self-Regulated Learning, Engagement/Motivation, Social Learning Environments and Serious Gaming, in the fields of Technology Enhanced Learning (TEL) and Computer Supported Collaborative Learning (CSCL). Contact : elise.lavoue@univ-lyon3.fr

Karim Sehaba is an Associate Professor of Computer Science at the University of Lyon 2 (France), member of LIRIS Lab. His main research interest lies in the field of Adaptive Serious Games. In this context, his research focuses on : user behaviour analysis based on interaction traces, interactive knowledge extraction and adaptation to the context of use. Contact : karim.sehaba@liris.cnrs.fr 